\title{
Long-range forecasting and the Global Framework for Climate Services
}

\author{
R. J. Graham ${ }^{1, *}$, W.-T. Yun ${ }^{2}$, J. Kim², A. Kumar ${ }^{3}$, D. Jones ${ }^{4}$, L. Bettio ${ }^{4}$, N. Gagnon ${ }^{5}$, \\ R. K. Kolli ${ }^{6}$, D. Smith ${ }^{1}$ \\ ${ }^{1}$ Met Office Hadley Centre, FitzRoy Road, Exeter EX1 3PB, UK \\ ${ }^{2}$ Korea Meteorological Administration, 460-18 Sindaebang-dong Dongjak-qu, Seoul 156-726, Republic of Korea \\ ${ }^{3}$ Climate Prediction Center, National Centers for Environmental Prediction, World Weather Building, Room 800, \\ 5200 Auth Road, Camp Springs, Maryland 20746-4304, USA \\ ${ }^{4}$ Australian Bureau of Meteorology, GPO Box 1289, 3001 Melbourne, Victoria, Australia \\ ${ }^{5}$ Meteorological Service of Canada, 2121 Trans-Canada Highway, Dorval, Québec H9P 1J3, Canada \\ ${ }^{6}$ Climate Prediction \& Adaptation Branch, Climate and Water Department, World Meteorological Organization, 7 bis Avenue \\ de la Paix, CP 2300, 1211 Geneva 2, Switzerland
}

\begin{abstract}
We describe the progress in the international coordination of long-range forecasting fostered by the World Meteorological Organisation (WMO), specifically for the seasonal to interannual timescale. Coordination has been achieved through the creation of new infrastructure, notably 11 Global Producing Centres (GPCs) for long-range forecasts, and definition of operational standards in forecast output and associated material. Examples discussed show improvements to the integration, usefulness and operational delivery of long-range forecast products to the world-wide climate community. Products are in wide use, and cover both predictive information, up to 6 mo ahead, and verification information indicating forecast quality. Proposals for future expansions of the role of GPCs are discussed, with a view to addressing the challenges presented by the development of the Global Framework for Climate Services. In particular, implementation of regular WMO-coordinated Global Seasonal Climate Updates is proposed, to provide authoritative, readily accessible advice on the state of the global climate and prospects for the next season. In addition we argue that the skill benefits provided by decadal-range predictions initialised with the observed climate state, relative to uninitialised (IPCC-type) predictions, are sufficient to begin similar international coordination in multiannual-to-decadal prediction, through extending the role of those GPCs that are developing decadalprediction capability.
\end{abstract}

KEY WORDS: WMO $\cdot$ Long-range forecasts · Global Producing Centres $\cdot$ GPC $\cdot$ Global Framework for Climate Services · GFCS · Lead Centres · Seasonal forecasts · Decadal prediction

\section{INTRODUCTION}

Over the last 10 to $15 \mathrm{yr}$, a number of international centres have developed operational capabilities for global long-range prediction, typically for 3-mo-mean climate anomalies and to 6 mo ahead, using ensemble integrations of dynamical models. Working through its Expert Teams, the World Meteorological Organisation (WMO) has fostered coordination between these centres, leading to the establishment of new infra- structure within the Global Data Processing and Forecasting System (GDPFS) that improves both access to the forecast information and the usefulness of this information for generating climate services. New nodes within the GDPFS include 11 WMO-designated Global Producing Centres (GPCs) for long-range forecasts, which adhere to criteria for long-range forecast output and verification developed by the Expert Teams. Two associated Lead Centres have also been established that facilitate coordination and dissemina- 
tion of GPC information. We describe the current functions of the GPCs and the Lead Centres in Section 2 together with progress made in making practical use of their outputs.

International agreement to develop a Global Framework for Climate Services (GFCS), to help the global community better adapt to the impacts of climate variability and change, was established at the World Climate Conference-3 (WCC-3). The GFCS concept provides a renewed challenge for the GPCs and Lead Centres to tailor and disseminate seasonal forecast products to the global community. It also provides an impetus to extend the role of some GPCs to serve the demand for predictions on multiannual-todecadal ranges, which are key planning horizons for many users. In a response to these challenges we outline, in Section 3.1, a proposal to develop WMOcoordinated Global Seasonal Climate Updates (GSCUs). The GSCUs will synthesise information from GPCs and other global climate centres, including monitoring centres, to provide regular authoritative assessments of the current state of the global climate and outlooks for the season ahead. With regard to multiannual-to-decadal prediction, we argue in Section 3.2 that international coordination of decadal-range predictions (from systems that are initialised with the observed climate state) should now be formalised along similar lines as exist for seasonal forecasts, such that the GFCS and its users may benefit from the improved prediction skill such systems offer on decadal timescales relative to (uninitialised) IPCCtype scenarios. The discussions and recommendations are summarised in Section 4.

\section{GPCS AND ASSOCIATED LEAD CENTRES}

\subsection{GPCs}

Nominations for GPC status from centres active in long-range forecasting were first reviewed in December 2006 using the following basic criteria developed by the Expert Team for Extended and Long-range Forecasting (ET-ELRF) of the WMO Commission for Basic Systems (CBS).

To be designated a GPC, a centre must:

- have a fixed production cycle and time of forecast issuance;

- provide a minimum set of forecast products (detailed in Vol. I of the manual on the GDPFS; WMO 2010). Briefly, the minimum requirement is to provide, with global coverage and to at least 4 mo ahead, forecast probabilities for tercile categories of $2 \mathrm{~m}$ temperature, precipitation and (for GPCs operating coupled ocean-atmosphere systems) seasurface temperature (SST). Additionally, recommended provision includes forecasts for pressure at mean sea level (pmsl), temperature at $850 \mathrm{hPa}$, and 500 hPa height;

- provide verification information, using retrospective forecasts and diagnostic measures defined by the WMO Standard Verification System for Long-Range Forecasts (SVSLRF). The core diagnostics of the SVSLRF are Relative Operating Characteristic (ROC) Scores, reliability and sharpness diagrams and (for deterministic forecasts) the Mean Square Skill Score (MSSS) (see Appendix II-8 of the manual

Table 1. WMO Global Producing Centres (GPCs) at the time of writing, with summary information of the forecast system configurations (more details available at www.wmolc.org). Column 4 shows the resolution of the atmospheric component of the prediction systems, using wave number truncation (' $\left.\mathrm{T}^{\prime}\right)$ or latitude/longitude grid spacing, as appropiate. The number of vertical model levels is preceded by 'L'. Note: GPC CPTEC (Centre for Weather Forecasts and Climate Studies, Sao Paulo, Brazil) was designated in June 2010 (after submission of this paper), bringing the total number of GPCs to 12

\begin{tabular}{|c|c|c|c|c|}
\hline GPC name & Centre & $\begin{array}{l}\text { System configuration } \\
\text { (ensemble size of forecast) }\end{array}$ & $\begin{array}{l}\text { Resolution } \\
\text { (atmospheric component) }\end{array}$ & $\begin{array}{l}\text { Hindcast } \\
\text { period used }\end{array}$ \\
\hline Beijing & Beijing Climate Centre & Coupled (48) & T63/L16 & 1983-2004 \\
\hline ECMWF & $\begin{array}{l}\text { European Centre for Medium } \\
\text { Range Weather Forecasts }\end{array}$ & Coupled (41) & T159/L62 & $1981-2005$ \\
\hline Exeter & Met Office Hadley Centre & Coupled (42) & $1.25^{\circ} \times 1.85^{\circ} / \mathrm{L} 38$ & $1989-2002$ \\
\hline Melbourne & Australian Bureau of Meteorology & Coupled (30) & T47/L17 & $1980-2006$ \\
\hline Montreal & $\begin{array}{l}\text { Meteorological Service of } \\
\text { Canada }\end{array}$ & 2-tier (40) & $\begin{array}{l}\mathrm{T} 32 / \mathrm{T} 63 / \mathrm{T} 95 / 2.0^{\circ} \times 2.0^{\circ} \\
(4-\text { model combination) }\end{array}$ & 1969-2004 \\
\hline Seoul & Korean Meteorological Agency & 2-tier (20) & $\mathrm{T} 106 / \mathrm{L} 21$ & $1979-2007$ \\
\hline Tokyo & Japan Meteorological Agency & Coupled (51) & T95/L40 & $1979-2008$ \\
\hline Toulouse & Météo-France & Coupled (41) & T63/L91 & $1979-2007$ \\
\hline Washington & $\begin{array}{l}\text { National Centers for } \\
\text { Environmental Prediction }\end{array}$ & Coupled (40) & T62/L64 & $1981-2004$ \\
\hline Moscow & Hydromet Centre of Russia & 2 -tier $(10)$ & $1.1^{\circ} \times 1.4^{\circ} / \mathrm{L} 28$ & $1979-2003$ \\
\hline Pretoria & South African Weather Service & 2 -tier (6) & T42/L19 & $1983-2001$ \\
\hline
\end{tabular}


on the GDPFS and references therein; WMO 2010); - provide information on the prediction methodology used; and

- provide access to prediction and verification products via a website and/or by dissemination over the Global Telecommunications System.

The 11 WMO-designated GPCs at the time of writing are listed in Table 1, together with brief information on the prediction methodologies used.

\subsection{Lead Centres}

To assist the work of the GPCs, 2 Lead Centres have also been established: a Lead Centre for LongRange Forecast Multi-Model Ensemble prediction (LC-LRFMME) and the Lead Centre for SVSLRF (LCSVSLRF).

Long-range forecast products have developed largely independently at GPC centres, resulting in little uniformity in the data formats and forecast visualisation techniques used. Inter-comparison of forecast signals through data available from individual GPCs (including forecast visualisation products on GPC websites) has therefore been a cumbersome process, and this can discourage users from taking a wide consensus among models (either in subjective assessments or objective multi-modelling). The LC-LRFMME (www. wmolc.org; jointly operated by the Korean Meteorological Agency and NOAA's National Centers for Environmental Prediction, USA) has been established to overcome these difficulties by providing a 'one-stop shop' for GPC information. Its functions are designed around the following central themes:

- collect long-range forecast data from all GPCs each month;

- maintain a central portal from which forecast users (e.g. Regional Climate Centres [RCCs], National Meteorological and Hydrological Services [NMHSs], and Regional Climate Outlook Forums [RCOFs]; see Fig. 4) can access the GPC output in standard digital and graphical formats; and

- exploit the skill benefits from multi-model forecast methods (e.g. Hagedorn et al. 2005) by developing and providing multi-model forecast products, and promote research into techniques for combining predictions from different models.

Examples of graphical products and functionality available from the LC-LRFMME website are provided in Figs. 1 \& 2. Fig. 1 shows ensemble-mean pmsl anomalies for northern winter 2009-2010 predicted, from November 2009, by 10 GPCs, and illustrates the typical variations in forecast signals. The multi-model ensemble mean (Fig. 2a) and a consensus product indicating the number of GPCs predicting the same anomaly sign (Fig. 2b) extract the dominant signals. The purpose here is to illustrate the functionality of the website facility rather than to discuss the forecast example, and single cases should not be used to infer the prediction skill. However, it may be noted that the forecast signals in Fig. 2a,b show a degree of success in detecting the negative-phase Arctic Oscillation that dominated the period (Fig. 2c) - though the forecast amplitude (Fig. 2a) underestimated that of the observed anomalies, as would be expected from an ensemble mean value. Further functionality is available that allows multi-model products to be generated with any combination of individual models. This facility may be of use when, because of rapidly developing El Niño-Southern Oscillation (ENSO) conditions for example, separate consideration of signals from coupled and uncoupled systems may be desirable. Facilities for downloading digital forecast data from some GPCs are also available in addition to the visualisation products discussed here.

The availability of seasonal forecast products represents a relatively new development in operational forecasting. Consequently, many users and potential users of such products are currently unfamiliar with typical levels of prediction skill, which can vary substantially with model, region, season and forecast variable. Information allowing the comparison of GPC skill is therefore essential for prudent use of the forecasts. The key role of the LC-SVSLRF is to collate and display GPC hindcast verification diagnostics in standard formats that allow ready inter-comparison. The LC-SVSLRF (www.bom.gov.au/wmo/lrfvs) is jointly operated by the Australian Bureau of Meteorology and the Meteorological Service of Canada. The skill measures employed are those detailed in the WMO SVSLRF.

Increasing use of the GPC forecasts and associated LC-LRFMME products is being made at NMHSs and RCOFs (see e.g. Ogallo et al. 2008). To date there are 123 registered users of the LC-LRFMME, representing NMHSs and other centres from 49 countries. In the generation of RCOF consensus seasonal forecast products, information on the weight to be given to GPC forecasts (relative to regional statistical predictions, for example) is crucial. Subjective assessment of appropriate weighting to be applied may be obtained from the SVSLRF products. To illustrate, Fig. 3a,b shows ROC scores, available from the LC-SVSLRF website, pertaining to skill in predicting above-upper-tercile rainfall in the short-rains season (September to December) and long-rains season (March to May) over the Greater Horn of Africa. It is evident that skill is highest for the short-rains season, for which ROC scores exceed 0.7 over coherent areas, indicating that the forecasts successfully discriminate the wet (above-upper-tercile) events in $>70 \%$ of cases (Mason \& Weigel 2009). A 

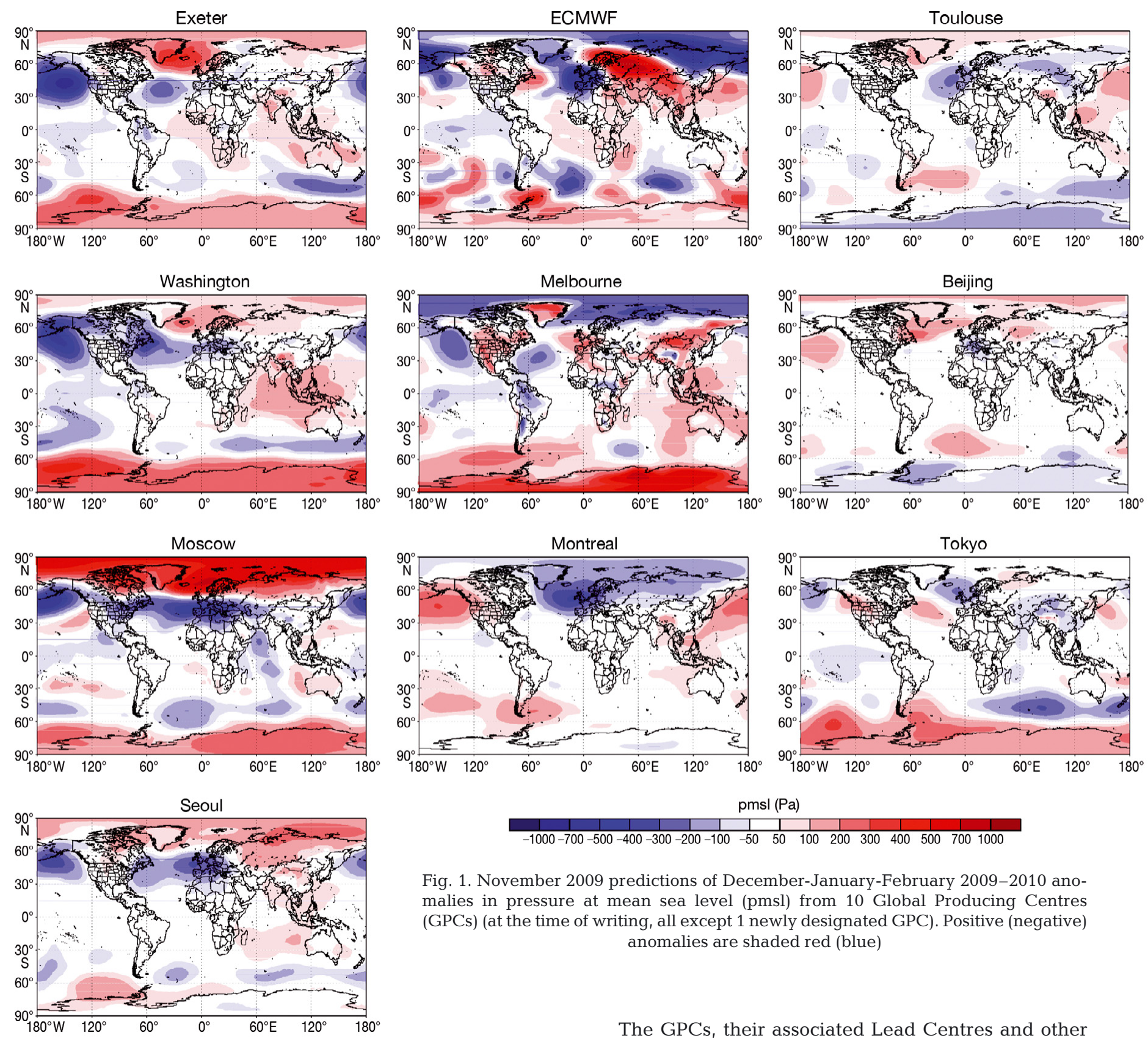

Fig. 1. November 2009 predictions of December-January-February 2009-2010 anomalies in pressure at mean sea level (pmsl) from 10 Global Producing Centres (GPCs) (at the time of writing, all except 1 newly designated GPC). Positive (negative) anomalies are shaded red (blue)

similar differential in prediction skill between the 2 seasons is found for the below-lower-tercile events and thus, in general terms, the GPC products can be used with greater weight for the short-rains season relative to the long-rains season. The example demonstrates the practicality of the SVSLRF information to regional/ national forecasters preparing seasonal outlooks. Further standardisation of the verification data sets and verification periods used by GPCs is being sought by the ET-ELRF and will enhance the utility of the skill information provided.
The GPCs, their associated Lead Centres and other nodes operating in the production of climate information collectively form the Climate Service Information System (Fig. 4) of the GFCS. The GPCs and Lead Centres are part of a wider group of Global Climate Centres that includes data-monitoring centres as well as other prediction centres that are not necessarily designated as GPCs. The main direction of information flow is from Global Climate Centres to regional nodes (RCCs and RCOFs), and onward to National Climate Centres (NCCs), which generally serve the end users. Value addition, e.g. through application of forecast downscaling and regional knowledge, occurs at each stage. 


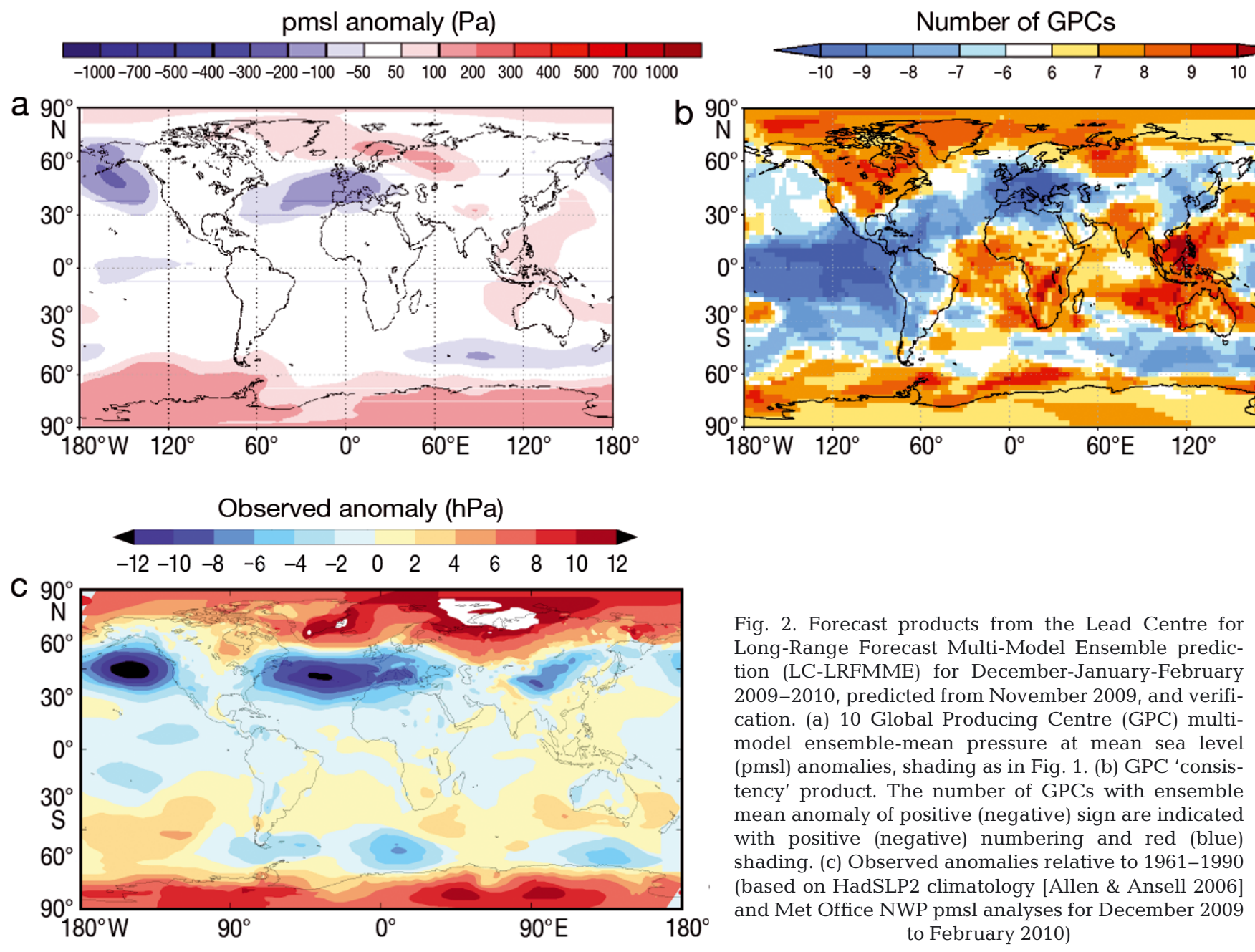

\section{NEW PERSPECTIVES FOR GPCs}

The development of the GFCS will bring new challenges to the provision of climate prediction and monitoring information. In this section we discuss 2 ways in which GPCs might extend their current roles in order to help realise the vision of the GFCS.

\subsection{GSCUs}

The progress in coordination of GPC predictions discussed in Section 2, and illustrated in Figs. 1 \& 2, now provides a basis for international cooperation in synthesising authoritative information on the expected evolution of climate indices and temperature and precipitation anomalies across the globe, including an assessment of attendant prediction uncertainties. To further the application of these advances, a WMOcoordinated initiative is proposed that will implement the regular issuing of GSCUs. The GSCUs would have
2 components: (1) a prediction component, based on GPC forecasts, and (2) a monitoring component reviewing the current state of the climate based on input from global climate-monitoring centres. It is envisaged that the GSCUs would be issued a few days ahead of the conventional 3 mo seasons (December to February, March to May, June to August, and September to November) and could be generated through a consensus among experts from GPCs, monitoring centres and RCCs. Inclusion of RCCs in the consensus process will be important to facilitate harmonisation with regional/ national outlooks. A similar consensus approach is already used for the currently issued WMO World Climate Applications and Services Programme (WCASP) El Niño/La Niña updates, and the GSCUs would complement and significantly extend the information disseminated in this existing product.

The balance of text and graphical visualisation employed in the GSCUs needs careful consideration. The potential for misinterpretation of text-based translations of probability information cannot be underesti- 
ROC score
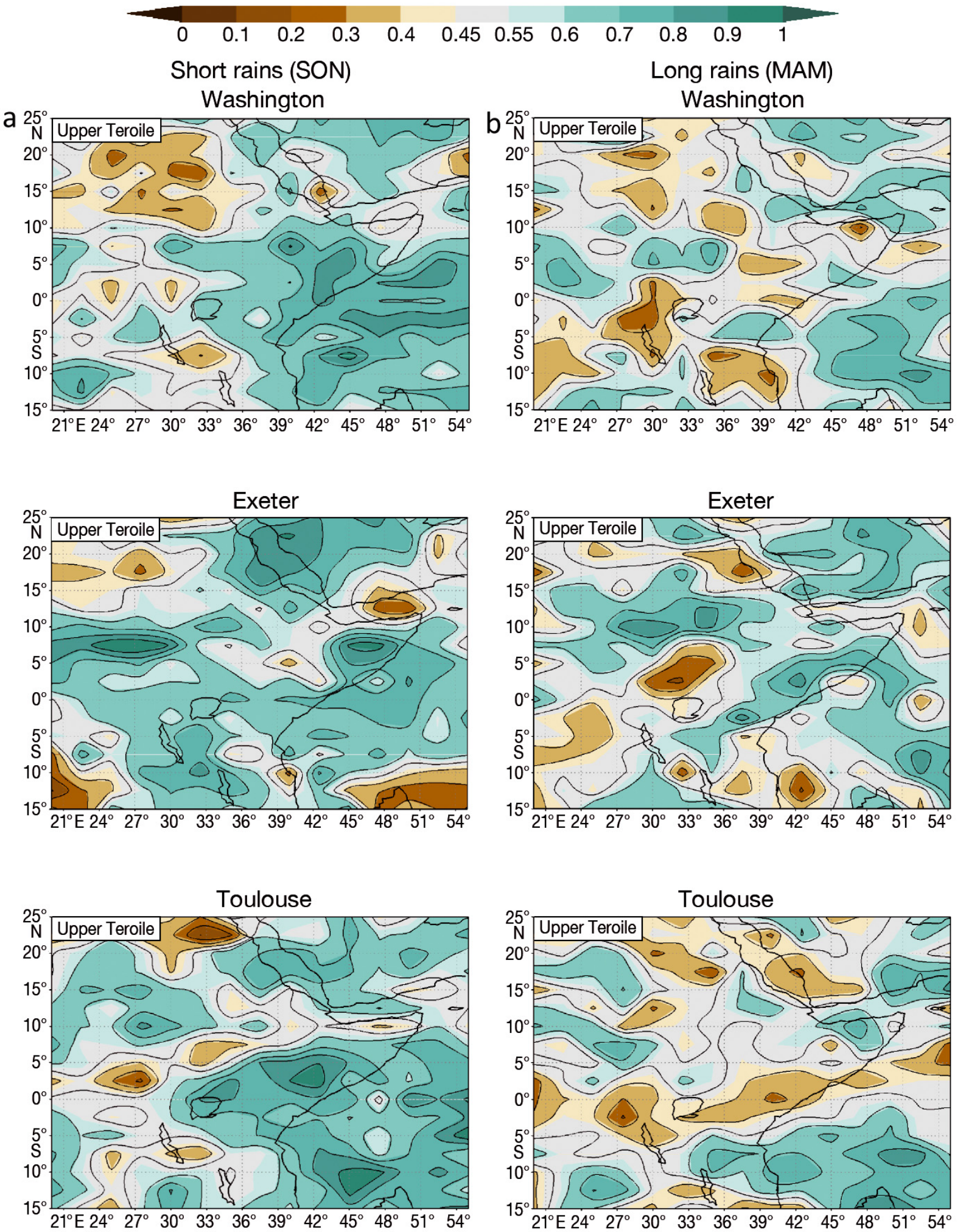

Fig. 3. Relative Operating Characteristic (ROC) scores for probabilistic predictions of above-upper-tercile precipitation over the Greater Horn of Africa region: (a) the September-November period of the short-rains season; (b) March-May (the long-rains season). Scores are (in rows top to bottom) for the Global Producing Centres (GPCs) Washington, Exeter and Toulouse. Note: the hindcast verification periods and verification data sets used differ across GPCs 


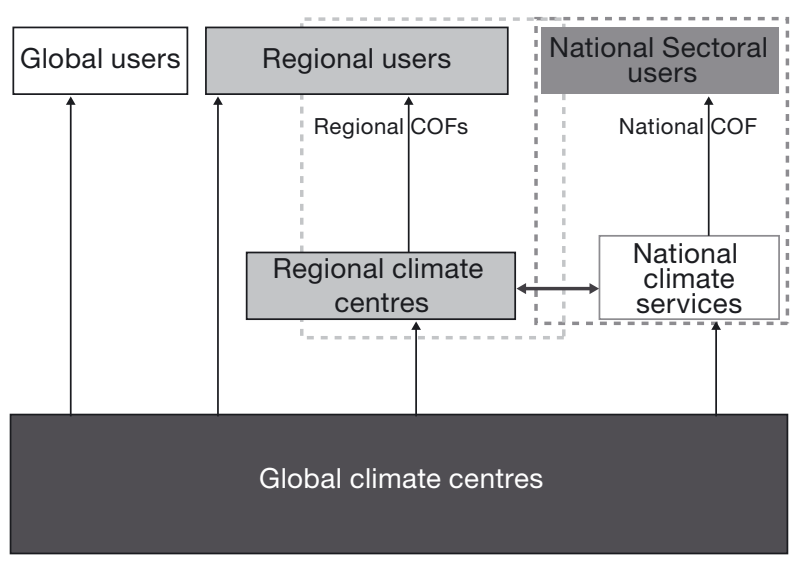

Fig. 4. The WMO Climate Service Information System illustrating the flow of climate information from global centres to regional and national centres and users. The Global Climate Centres include prediction centres, such as the Global Producing Centres (GPCs), their associated Lead Centres, and global climate-monitoring centres. COF: Climate Outlook Forum. (From draft 'Position Paper on Global Framework for Climate Services' at www.wmo.int/pages/gfcs/index_en.html)

mated. It is common experience that users frequently place undue emphasis on the outcome with the highest predicted probability, and neglect to plan appropriate contingencies based on substantial (but lower) probabilities of other outcomes. For the seasonal prediction component of the GSCUs, a graphical presentation based on multi-model products from the LC-LRFMME is therefore an attractive option. Brevity and simplicity will be desirable, and products that condense information on signals and uncertainty might be a useful approach. The multi-model ensemble-mean and consistency plots produced for the IPCC 4th Assessment Report (IPCC 2007, their Fig. SPM.7) are well-known, and presumably well-understood, examples of such products and it might be profitable to adapt this format for use in the GSCUs.

Further underpinning work that will support the GPC multi-model basis for the GSCUs is being scheduled by the ET-ELRF. For example, at present, provision of GPC data to the LC-LRFMME is largely limited to predicted anomalies pre-calculated from hindcast data by the GPCs. For generation of comprehensive probabilistic multi-model products, the provision of data to the LC-LRFMME should be extended to both forecasts and hindcasts. Additionally, the SVSLRF verification diagnostics (Fig. 3) should be applied also to multi-model products as well as to the individual GPCs and made available to users to allow ready assessment of the multi-model skill.

The key target users of GSCUs will include RCCs, RCOFs and NMHSs as well as be users of seasonal climate information that operate within a global context (e.g. organisations involved in international aid and disaster risk management). Through the combination of monitoring and prediction components, GSCUs will help promote early awareness of potential climate 'hotspot' regions. This will help direct users to the products of RCCs, RCOFs and NMHSs in the impacted regions for more spatio-temporal detail and more frequent updates.

\subsection{Interannual-to-decadal prediction}

Many sectors have planning timescales of order 5 to $10 \mathrm{yr}$, and it is important that the GFCS develops capabilities and services for prediction on this decadal timescale-though capability at this range is currently less developed than for seasonal forecasting.

At the multiannual-to-decadal range, natural lowfrequency variability and anthropogenically forced changes may be of similar magnitude in many regions. Initialised climate prediction systems are therefore needed so that predicted changes are informed both by projected greenhouse-gas emissions and by the predicted evolution of current observed phases of natural variability (on decadal and other timescales). Uninitialised predictions covering the decadal range (such as those available from the IPCC 4th Assessment) take account of greenhouse gas forcing-but natural variability in such projections is unconstrained by observation.

Using the Met Office's decadal prediction system DePreSys, Smith et al. (2007) demonstrated that initialisation improves skill in decadal-range prediction of global mean temperature. There is good evidence that initialisation also improves skill at regional scales, particularly at multi-annual ranges. The largest skill gains are found for temperature predictions, but improvements are also evident for precipitation, as may be appreciated from Fig. 5, which compares correlation skill assessments for DePreSys ensemblemean predictions of annual precipitation with corresponding uninitialised (NoAssim) predictions.

A number of centres are developing initialised seasonal-to-decadal prediction systems. Predictive information that is superior, at least for the first decade ahead, to that available from IPCC-type scenarios is therefore becoming available, and it is now timely to initiate international coordination in decadal prediction along similar lines to that established for seasonal prediction. To support this coordination, an extended remit for GPCs developing decadal capabilities could be defined.

In addition to needing longer timescales, many users also have a requirement for intra-seasonal (monthlyrange) forecasts. This need has been recognised by 


\section{Pearson's correlation coefficient

$\begin{array}{lllllll}-0.6 & -0.4 & -0.2 & 0 & 0.2 & 0.4 & 0.6\end{array}$

\section{DePreSys:Year 1}

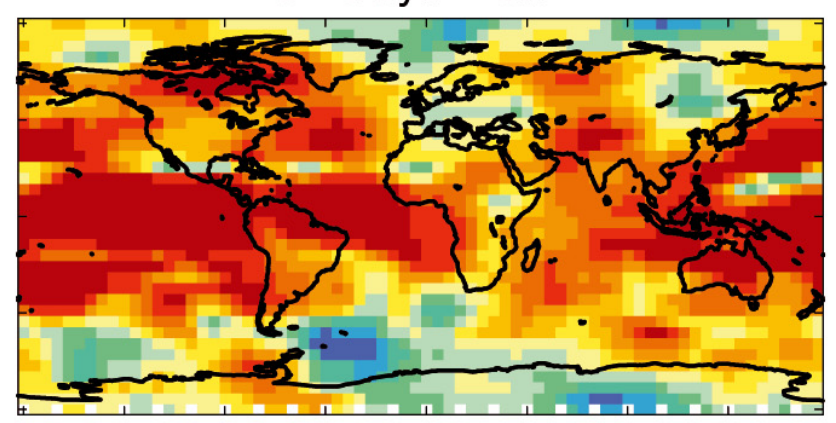

DePreSys:Year 2
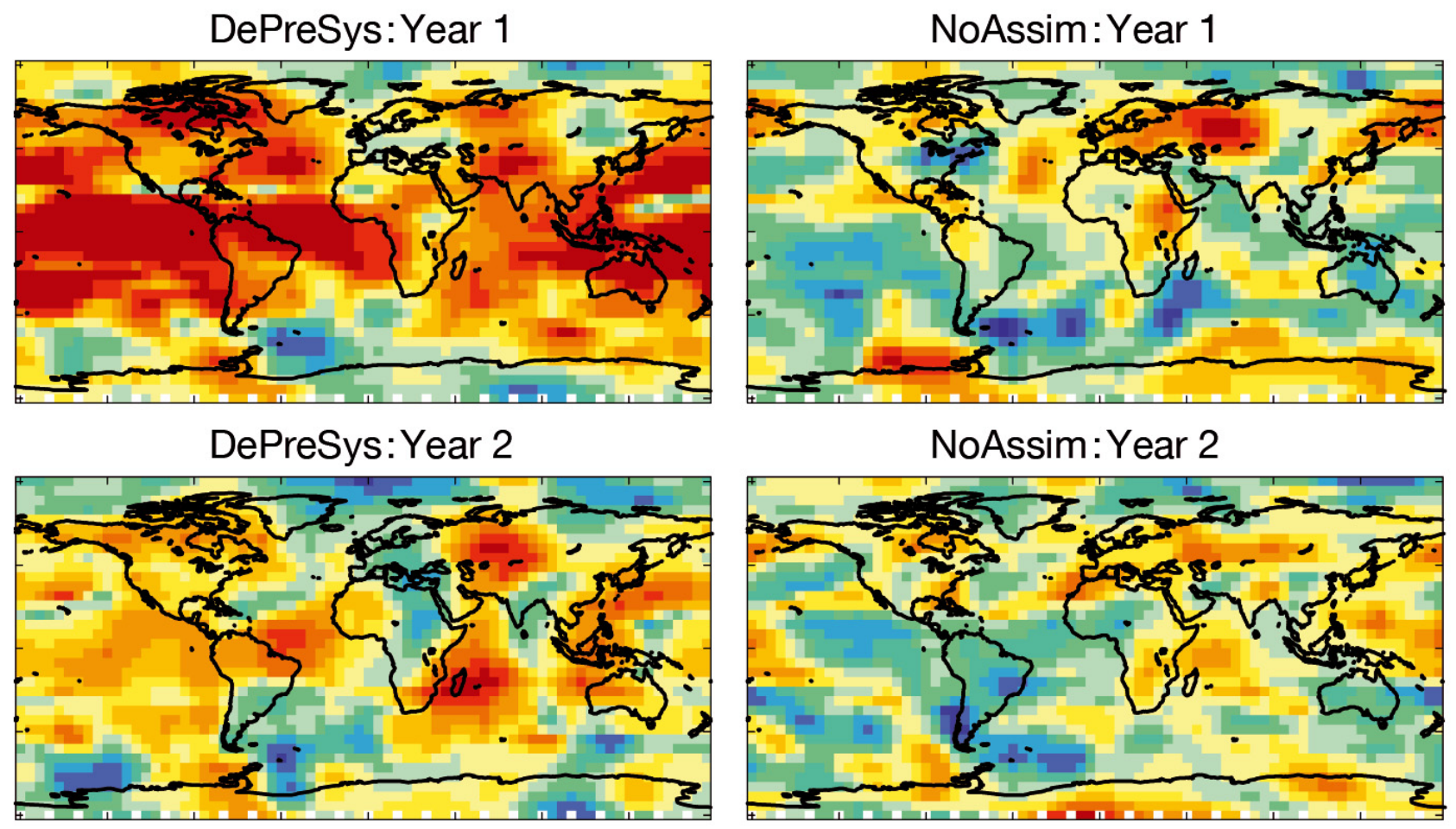

NoAssim:Year 2

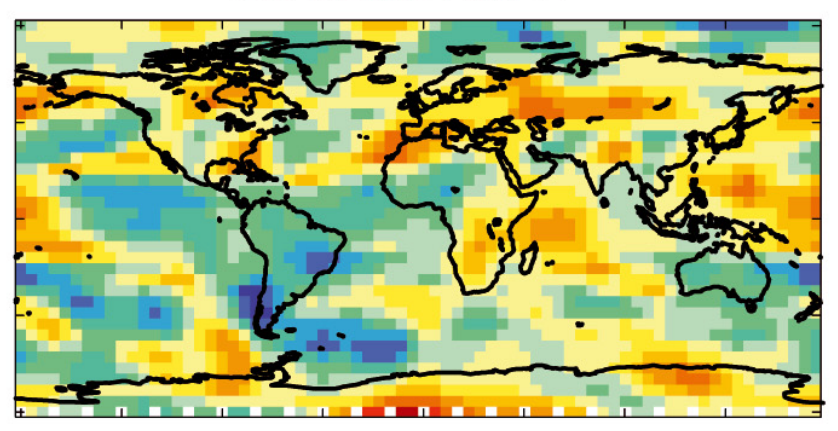

Fig. 5. Correlation between observed (GPCP; Adler et al. 2003) and predicted ensemble-mean annual precipitation anomalies. Each pixel shows the correlation of regional averages (over a $35^{\circ} \times 35^{\circ}$ latitude/longitude box) centred on that pixel and calculated over a set of hindcasts starting each November from 1979 to 2005. Left: correlations from the Met Office's decadal prediction system DePreSys. Right: correlations achieved with a corresponding system with no assimilation of the initial state, NoAssim. Both DePreSys and NoAssim predictions are the ensemble mean of a 9-member ensemble. Top and bottom rows show correlations for the first and second year of the hindcasts, respectively

CBS, and a review of the potential for coordination in extended-range forecasting, an operational activity at some centres (e.g. Vitart 2004), is already within the terms of reference of the ET-ELRF.

\section{SUMMARY}

Working through its Expert Teams, the WMO has established GPCs and associated lead centres (LCLRFMME and LC-SVSLRF) to facilitate access to longrange forecast information and to improve its usefulness for generating climate services. GPC and Lead Centre products are in use by NMHSs, RCCs and RCOFs, with 123 registered users in 49 countries. A programme for continued improvement of functionality of the services provided by GPCs is being developed by the WMO CBS ET-ELRF.

The GFCS presents new challenges to the GPCs to expand services to users, both by improving the application and dissemination of existing predictions, and by bringing new prediction methodology into operation. To help meet these challenges, it is proposed that GSCUs be developed, based on prediction information from GPCs and global monitoring data from other global centres, that will provide users with authoritative and readily accessible advice on the current state of the global climate and prospects for the upcoming season. In addition we propose that international coordination of interannual-to-decadal predictions be initiated along the lines now established for seasonal forecasting. This will facilitate access to initialised decadal predictions-which have improved prediction skill, relative to uninitialised (IPCC-type) predictions on the decadal timescale-and accelerate development of multi-model products.

Acknowledgements. We thank the many participants in the international activity summarised here, including representatives of the GPCs and Lead Centres, members and associate members of the WMO CBS ET-ELRF (past and present) and the WMO secretariat for guidance and encouragement. 


\section{LITERATURE CITED}

Adler RF, Huffman GJ, Chang A, Ferraro R and others (2003) The Version 2 Global Precipitation Climatology Project (GPCP) monthly precipitation analysis (1979 to present). J Hydrometeorol 4:1147-1167

Allan R, Ansell T (2006) A new globally complete monthly historical gridded mean sea level pressure dataset (HadSLP2): 1850-2004. J Clim 19:5816-5842

Hagedorn R, Doblas-Reyes FJ, Palmer TN (2005) The rationale behind the success of multi-model ensembles in seasonal forecasting. 1. Basic concept. Tellus 57A: $320-339$

IPCC (2007) Summary for policymakers. In: Solomon S, Qin D, Manning M, Chen Z and others (eds) Climate change 2007: the physical science basis. Contribution of Working Group 1 to the Fourth Assessment Report of the Intergov-

Submitted: May 2, 2010; Accepted: October 19, 2010 ernmental Panel on Climate Change. Cambridge University Press, Cambridge

Mason SJ, Weigel AP (2009) A generic forecast verification framework for administrative purposes. Mon Weather Rev 137:331-349

Ogallo L, Bessemoulin P, Ceron JP, Mason S, Connor SJ (2008) Adapting to climate variability and change: the Climate Outlook Forum process. WMO Bull 57:93-102

Smith DM, Cusack S, Colman AW, Folland CK, Harris GR, Murphy JM (2007) Improved surface temperature prediction for the coming decade from a global climate model. Science 317:796-799

Vitart F (2004) Monthly forecasting at ECMWF. Mon Weather Rev 132:2761-2779

WMO (2010) Manual on the Global Data-processing and Forecasting System. WMO, Geneva. www.wmo.int/pages/ prog/www/DPFS/Manual_GDPFS.html

Proofs received from author(s): March 18, 2011 